\title{
Prácticas culturales y sensibilidades políticas en la concreción de proyectos regionales: el Colegio Libre de Estudios Superiores a mediados del siglo XX
}

[Cultural practices and political sensitivities in the realization of regional projects: the Colegio Libre de Estudios Superiores in the middle of the 20th century]

\author{
Juliana López Pascual
}

(Centro de Estudios Regionales/Departamento de Humanidades/Universidad Nacional del Sur - Consejo Nacional de Investigación Científicas y Técnicas) juliana.lopezpascual@uns.edu.ar

\begin{abstract}
Resumen:
El presente artículo procura abordar el estudio del Colegio Libre de Estudios Superiores a través de la reconstrucción de su experiencia institucional específica, de la caracterización de su política cultural y de sus relaciones con el mundo partidario. De la exploración documental se desprende que la dimensión regional constituyó tanto un eje teórico fundamental como una herramienta de proyección y expansión de la iniciativa intelectual desde 1940. Esto se observa, particularmente, en el análisis de la trayectoria de la filial ubicada en Bahía Blanca, sudoeste de la provincia de Buenos Aires, cuyo accionar estimuló y, simultáneamente, se encabalgó en el fortalecimiento de los espacios de la sociabilidad cultural local y en el sostenimiento de sus proyectos de centralidad sobre la Norpatagonia.
\end{abstract}

Palabras claves: Colegio Libre de Estudios Superiores; Historia Cultural; Bahía Blanca; Región; Sociabilidad Cultural

\begin{abstract}
:
This article seeks to approach the study of the Colegio Libre de Estudios Superiores through the reconstruction of its specific institutional experience, the characterization of its cultural policy and its relations with the partisan world. The documentary exploration shows that the regional dimension constituted both a fundamental theoretical axis and a tool for the projection and expansion of intellectual initiative since 1940. This is observed, particularly, in the analysis of the trajectory of the subsidiary located in Bahía Blanca, southwest of the province of Buenos Aires, whose actions stimulated and, simultaneously, were embedded in the strengthening of the spaces of local cultural sociability and in the support of its centrality projects on the northern Patagonia.
\end{abstract}

Keywords: Colegio Libre de Estudios Superiores; Cultural History; Bahía Blanca; Region; Cultural Sociability

Recibido: 18/02/19

Evaluación: 14/05/19

Aceptado: 08/08/19

Anuario de la Escuela de Historia Virtual - Año 11 - № 17 - 2020: pp. 79-103.

ISSN: 1853-7049

http://revistas.unc.edu.ar/index.php/anuariohistoria 


\section{Prácticas culturales y sensibilidades políticas en la concreción de proyectos regionales: el Colegio Libre de Estudios Superiores a mediados del siglo $\mathrm{XX}^{1}$}

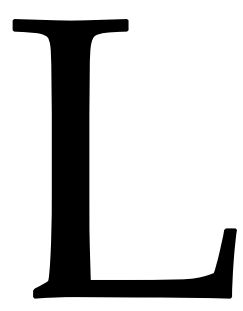

os estudios sobre políticas culturales han probado ser, en los últimos años, un nicho fundamental en la reformulación de los temas de la Historia Cultural así como también han constituido una dimensión importante en la renovación de las investigaciones sobre lo político, la esfera partidaria, el mundo asociativo y el desarrollo del Estado en todos sus niveles (Sirinelli, 1998; Agesta y López Pascual, 2018). Asimismo, la cuestión resulta particularmente interesante si se hace foco en los años de la segunda posguerra, tanto por el "momento Malraux", la ya casi paradigmática institucionalización francesa (Négrier, 2003; Poirrier, 2000), como por las formas en las que se produjo la articulación entre las dirigencias políticas, los intelectuales, la sociedad civil y las burocracias culturales en algunos casos latinoamericanos (Fiorucci, 2004). En Argentina, la construcción y consolidación del fenómeno peronista durante los años 40, sus interpretaciones contemporáneas y la elaboración de los relatos posteriores estuvieron, en efecto, intrínsecamente atravesadas por esas variables en tanto el mundo letrado se vio interpelado a adoptar posiciones frente a la instalación y el desarrollo de un proyecto que tensionaba los vínculos entre el campo cultural y el político, a la vez que configuraba y definía nuevos espacios y orientaciones para la gestión de sus prácticas (Fiorucci, 2011). En este sentido, el establecimiento de posturas antagonistas frente al movimiento liderado por Juan Domingo Perón han sido entendidas, en su mayor parte y con clara evidencia, como la deriva lógica de una lectura en clave antifascista que recuperaba las experiencias europeas frente a los regímenes totalitarios y las alineaba a la tradición liberal heredada de la Reforma Universitaria (Altamirano, 2001; Sigal, 2002; Pasolini, 2013). Menos atención se ha prestado, sin embargo, a los variados matices y a las formas regionales en que la sociedad civil respondió a las propuestas estatales de intervención pública en un terreno hasta entonces librado a la acción de sujetos y entidades que, en no pocos casos, se desprendían de la tradición política

\footnotetext{
${ }^{1}$ El presente trabajo constituye un avance de la investigación “Sociabilidad, redes sociales y asociacionismo en la construcción de la imagen de Bahía Blanca como "capital de la Patagonia" (1940-1970)", realizada en el marco de los proyectos de investigación “Culturas políticas y sociedad en Bahía Blanca durante el siglo XX" (código 24/I248UNS), coordinado por Dra. Patricia Orbe y acreditado para el período 2017 - 2020 y “Arte y cultura en Bahía Blanca: tensiones y debates entre la institucionalización y la emergencia" (Código 24/I230 - UNS), dirigido por Dra. Diana I. Ribas y acreditado durante el período 2015 - 2018, ambos con sede en el Departamento de Humanidades de la Universidad Nacional del Sur. Una versión inicial y exploratoria de este artículo fue presentada en el Taller "Hacia una agenda de problemas para los estudios sobre el socialismo en el interior" - Universidad Nacional de Mar del Plata, noviembre de 2018. Agradezco los comentarios y las sugerencias entonces realizados por Andrés Bisso.
} 
de izquierdas y que, de manera permanente, actualizaba y reeditaba tensiones entre áreas hegemónicas y espacios relativamente periféricos.

Desde esa perspectiva, la reconstrucción y el análisis de proyectos culturales como el del Colegio Libre de Estudios Superiores se presentan como la oportunidad de problematizar estas miradas a la vez que conduce necesariamente, por las características específicas de su iniciativa, a revisar la cuestión atendiendo a las particularidades que ella adoptó en diferentes tiempos y espacios. En efecto, el proceso de descentralización de sus actividades iniciado en 1941, luego de una década de funcionamiento circunscripto a la Capital Federal, buscó transformar la escala de acción institucional y, en provecho de los lazos personales de sus miembros, creó sedes del CLES en algunas ciudades del interior del país como Entre Ríos, Córdoba, Tucumán, Santiago del Estero, La Plata, Santa Fe, Mendoza, Bahía Blanca y Rosario, pocas de las cuales perduraron hasta fines de los años 60 .

Este fue el caso de la filial ubicada en la localidad bonaerense de Bahía Blanca, conducida desde sus inicios por el abogado y dirigente socialista Pablo Lejarraga, cuya trayectoria política se desarrolló en simultaneidad y con intensidad similar a su participación en iniciativas culturales (López Pascual, 2016a). En este artículo, procuraremos analizar elementos relativos a esa experiencia institucional prolongada, múltiple y compleja en la que el desarrollo y sostenimiento de políticas culturales dialogaba de manera íntima -valga el juego de palabrascon la dinámica de las culturas políticas, entendiendo que una de sus especificidades radicaba en su vinculación a la polémica, pero potente, concepción de esta ciudad como espacio central de la región patagónica.

\section{El Colegio Libre de Estudios Superiores en perspectiva multiescalar}

Aunque constituye un elemento de referencia casi obligada para quienes estudian el mundo de la cultura letrada de mediados del siglo XX en Argentina, el Colegio Libre de Estudios Superiores ha sido objeto de una acotada cantidad de investigaciones (Neiburg, 1998; Cernadas, 1999 y 2006). Siempre sugerida la centralidad de su gravitación en el escenario intelectual y político de la época, su estudio suele ser elusivo, probablemente por la magnitud y la extensión de la empresa, lo que deriva de las formas específicas que cobró la institución por la misma voluntad de irradiar sus esfuerzos en todo el territorio nacional, así como por las dificultades para la reconstrucción documental de su heterogénea experiencia. ${ }^{2}$

Como es sabido, la interrupción constitucional que supuso el derrocamiento de Hipólito Yrigoyen en septiembre de 1930 impactó, entre otras dimensiones, en el seno del mundo

\footnotetext{
${ }^{2}$ En la mayoría de los casos, la vida del Colegio suele abordarse a partir del trabajo sobre su revista, Cursos y conferencias, en la que se publicaron los textos de las disertaciones y someras reseñas de las actividades. El análisis intrainstitucional resulta menos frecuente, en parte, a raíz de la dispersión y la escasez documental. Contrariamente a la mayoría de las filiales, la sede de Bahía Blanca conservó sus archivos epistolares y memorias anuales de manera casi completa, fuentes que hoy están al resguardo de la Biblioteca Marasso del Departamento de Humanidades de la UNS y que se convierten, entonces, en un material fundamental para la reconstrucción de la entidad.
} 
cultural, sus actores e instituciones. Expulsados, removidos, cesanteados, perseguidos o encarcelados por el proyecto uriburista, algunos de los artistas, estudiantes e intelectuales comprometidos con el ideario democrático y liberal debieron gestionar nuevos espacios de trabajo, a la vez que instrumentar de modos novedosos los vínculos personales establecidos en épocas pasadas (Sigal, 2002). En ese contexto, y como respuesta al mismo, en 1931 Roberto F. Giusti, Aníbal Ponce, Carlos Ibarguren, Alejandro Korn, Narciso C. Laclau y Luis Reissig crearon el CLES en la Capital Federal, interesados en el desarrollo de lo que denominaron "cultura superior". De manera análoga a los espacios culturales asociados a la intelectualidad socialista -como la Universidad Popular "Alejandro Korn" o la Escuela de Estudios Sociales "Juan B. Justo"- en los que algunos de ellos también participaban, una de las prácticas más consolidadas dentro de la institución fue la del dictado de cursos según la modalidad de "cátedra libre", lo que permitió a los diferentes miembros intervenir en las actividades, en calidad de docentes o formando parte del público. ${ }^{3}$ Asimismo, la creación del Colegio quedaba marcada por la participación de la mayoría de sus miembros iniciales en la Reforma Universitaria de 1918, la vinculación con el frente antifascista y la oposición general al proyecto universitario corporativo (Graciano, 2003; Di Stefano, Sábato, Romero y Moreno, 2002; Nallim, 2012). ${ }^{4}$ De allí que los planteos académicos desarrollados se estructuraron sobre una base de orientación progresista y liberal, que implicó tomar posición en el debate social y político mayor que habían abierto las experiencias europeas autoritarias, pero también frente al crecimiento de los sectores militares golpistas, conservadores y católicos integristas en la escena argentina a partir de 1930 (Halperin Donghi, 2003).

Luego de casi una década de trabajo, la institución encaró una transformación cualitativa. Por un lado, se produjeron algunos contactos con esferas públicas que permitieron proyectar cierto crecimiento material; en 1940, el Concejo Deliberante de la Capital Federal le otorgó excepcionalmente una subvención económica de $\$ 700^{5}$ y le concedió el uso de un solar en el que la entidad construiría su edificio propio, mediante la injerencia de la Comisión de Obras Públicas. Estos planes, de por sí debatidos entre el cuerpo de concejeros y la intendencia, se vieron frustrados por el movimiento político de 1943, que, entre otras cosas, suspendió las actividades del poder legislativo (CLES, 1953: 9). Por otro lado, la dirección del Colegio buscó

\footnotetext{
${ }^{3}$ Como es posible observar en las páginas de Cursos y conferencias, por este espacio circularon Francisco y José Luis Romero, Arturo y Risieri Frondizi, Jorge Luis Borges, Bernardo Canal Feijóo, Ricardo M. Ortiz, Jorge Thénon, Gabriel del Mazo, Ernesto Sábato, Américo Ghioldi, Arnaldo Orfila Reynal, Carlos Alberto Erro, Alfredo Palacios, José Peco, Adolfo Dorfman, Juan Antonio Solari, Juan José Díaz Arana, entre muchos otros, en diferentes instancias, tiempos y formas de participación.

${ }^{4}$ En cierta forma es posible, incluso, relacionar las inquietudes de estos intelectuales argentinos con la trayectoria de los liberales krausistas españoles en la Institución Libre de Enseñanza y su proyecto pedagógico, a fines del siglo XIX. La ILE funcionó en España entre 1876 y 1936, momento en que sus directivos fueron obligados al exilio. Fue fundada por docentes liberales expulsados de la Universidad Central de Madrid, entre los que se hallaban Francisco Giner de los Ríos, Gumersindo de Azcárate, Teodoro Sainz Rueda y Nicolás Salmerón (Álvarez Lázaro, 1999).

${ }^{5}$ Desde su fundación, la existencia del Colegio se financió a partir del cobro de una cuota a los asistentes a los cursos y de la recepción de donaciones (CLES, 1953, p. 9). La suscripción anual a Cursos y conferencias se convirtió, en el largo plazo, en una buena fuente de ingresos estables.
} 
descentralizar las actividades, adquirir una mayor envergadura y dotar de cierta sistematización a sus tareas a partir de la redacción de un estatuto. En este sentido y aprovechando los lazos personales de sus miembros, se crearon sedes en algunas ciudades del interior del país como Entre Ríos, Córdoba, Tucumán, Santiago del Estero, La Plata, Santa Fe, Mendoza y Rosario. ${ }^{6} \mathrm{Si}$ bien la selección de las localidades probablemente estuviera condicionada por la preexistencia de vínculos individuales entre los miembros capitalinos y las personalidades locales -como fue el caso del abogado Pablo Lejarraga, quien había participado del movimiento reformista en las universidades de Buenos Aires y La Plata y formaba parte de los cuadros del Partido Socialista, o el de Horacio Rava, escritor santiagueño vinculado a la Sociedad Argentina de Escritores y a la Agrupación de Intelectuales, Artistas, Periodistas y Escritores,$-{ }^{7}$ es posible que las características socioeconómicas de la población y el desarrollo de sus organizaciones hayan constituido una variable a atender.

Fue de esta forma como el 9 de agosto de 1941 se convocó a la primera reunión para formar la filial Bahía Blanca en la que Lejarraga se desempeñó como secretario general hasta su disolución a principios de la década de 1970. Los Consejos Directivo y Consultivo locales fueron integrados por docentes, miembros de otras instituciones culturales, escritores, periodistas, profesionales y personalidades con trayectoria política dentro de partidos como la UCR y el PS y, sobre todo, con una intensa participación en variadas formas de sociabilidad. ${ }^{8}$ La creación de la sede -fruto de la voluntad capitalina- halló eco en una sociedad civil que ya se encontraba inmersa en un proceso general de movilización asociativa, lo que se volvió crucial para el éxito y la perdurabilidad del proyecto. En efecto, los años 40 se evidencian como una década en la que la voluntad de agregación, que había caracterizado de manera creciente a la comunidad bahiense desde los inicios del siglo XX (Agesta, 2014), manifestaba una gran vitalidad y una creciente especialización, a la vez que mostraba los resultados de las gestiones realizadas en los años previos. Hacia mediados de la década, la localidad se había convertido en una ciudad de 122.000 habitantes entre los que las inquietudes sociales, deportivas, profesionales, culturales, políticas, económicas y gremiales habían conducido a la consolidación y multiplicación de los espacios de la sociedad civil, que vio así crecer el número de participantes en ella a la vez que se diversificaban sus formas institucionales. Fue en ese contexto específico en el que la iniciativa del CLES fue bien recibida y acompañada: tanto Lejarraga, como Gregorio Scheines o Fermín Moisá ya lideraban y convocaban a la acción

\footnotetext{
${ }^{6}$ El estudio de estas filiales es aún muy incipiente -v.g. Guzmán (2014), para el caso de Santiago del Estero, y Fernández (2019), para Rosario- y son escasas las investigaciones que abordan aspectos de esta dispersión institucional.

${ }^{7}$ Sobre la filial santiagueña puede consultarse Guzmán (2014).

${ }^{8}$ El primero estaba formado por Zulema Cornídez, Orlando Erquiaga, Germán García, Berta Gaztañaga, Ismael E. Ricci, Gregorio Scheines y Miguel Ángel Torres Fernández, mientras que para el órgano consultivo fueron convocados Agustín de Arrieta, Santiago Bergé Vila, Carlos E. Cisneros, Prudencio R. Cornejo, Sara Curth de Torres, Ramón del Río, Mario M. Guido, Arturo B. Kiernan, Dorotea Macedo de Steffens, Fermín R. Moisá, Alberto Savioli y Ernesto Sourrouille.
} 
organizada en otros espacios de sociabilidad ${ }^{9}$ con un perfil social mayoritario similar al que tendría el Colegio, es decir, sujetos masculinos que desempeñaban profesiones liberales y se vinculaban en mayor o menor grado a los círculos partidarios del radicalismo y el socialismo (López Pascual, 2015a).

Desde sus inicios y como actividades preponderantes, el CLES llevó adelante una agenda de trabajo cultural que, como mencionamos, recuperaba en buena parte las prácticas que ya eran distintivas del accionar de los grupos de librepensadores, consistentes en la realización de cursos o conferencias magistrales por parte de especialistas o idóneos destinados a un público general, la visita de intelectuales y la edición y publicación de revistas y separatas de esos encuentros. La concreción de estos programas, por su parte, implicó, por un lado, la activación de los lazos personales preexistentes de los gestores dispersos en el resto del país casos como el de Lejarraga, Olga Cossettini, en Rosario, o Luis Reissig en Buenos Aires abonan esta hipótesis- ${ }^{10} \mathrm{y}$, por otro lado, la producción de vínculos nuevos que posibilitaran desplazamientos entre filiales y la circulación de oradores y disertantes (López Pascual, 2011a). En este sentido, el accionar general de la sede bahiense visibilizó la existencia de redes sociales, intelectuales e institucionales de distinta escala regional, que se superponían y articulaban entre sí, generando otras y poniendo en contacto a los mediadores culturales de las localidades del interior con la escena cultural porteña y platense por la que transitaban figuras de creciente reconocimiento académico e ideológico. ${ }^{11}$ En todas ellas, los bahienses adoptaban diversas estrategias en virtud de la disparidad de sus posiciones de centralidad y descentralidad, jugando así roles variables frente a la Capital Federal, la capital provincial, las localidades del sudoeste bonaerense, los Territorios Nacionales del área patagónica y la proyección latinoamericana.

En verdad, la atención a la escala de observación se vuelve fundamental para entender la experiencia del Colegio - particularmente en lo que atiende a sus aspectos políticos entendidos en un sentido amplio-, porque permite observar una serie de ejes que solo se distinguen a los efectos analíticos: la agenda de trabajo cultural y la forma en la que los sujetos concebían el alcance regional de sus actos.

\section{Planificaciones culturales, dimensión partidaria y coyunturas políticas}

En primer lugar, cabe observar el problema de las políticas culturales en sus relaciones con la dimensión partidaria. Como ya hemos esbozado, muchos de los integrantes del Colegio sostenían sensibilidades políticas más o menos cercanas a las izquierdas; sin embargo, la

\footnotetext{
${ }_{9}$ Entre ellos podrían mencionarse el Colegio de Abogados, la Cooperativa Eléctrica Bahiense, la Asociación Bernardino Rivadavia y varios clubes sociales y deportivos.

${ }^{10}$ Sobre la figura de Olga Cossettini puede verse Fernández (2019).

${ }^{11}$ Entre ellos podemos mencionar a Arnaldo Orfila Reynal, Francisco y José Luis Romero, Carlos Sánchez Viamonte, Ataulfo Pérez Aznar, Alfredo Palacios, Ricardo M. Ortiz, Adolfo Dorfman, Sergio Bagú y Aquiles Martínez Civelli. APL-UNS.
} 
agenda de trabajo parecía alejarse de esa esfera tanto en lo que hace al público como a sus objetivos declarados. De una parte, la iniciativa no se desarrollaba en espacios barriales ni sus destinatarios primordiales se circunscribían a las clases trabajadoras, aunque no los excluían; de hecho, aunque no es posible reconstruir las características de quienes circulaban por sus aulas, el perfil asociativo permite inferir que quienes tomaban parte en las actividades eran los vecinos de clase media profesional, estudiantes y algunos cuentapropistas. ${ }^{12}$

Por otro lado, las tareas emprendidas no solían presentarse como parte de la lógica partidaria o proselitista, ni los sujetos asumían -en ese ámbito- posturas que puedan identificarse como propias del "intelectual de partido", toda vez que, de manera fuerte, funcionaba el mandato de la prescindencia política en el seno de la cultura. Aquí, como en tantas otras iniciativas culturales, la cercanía a las pugnas electorales se concebía como parte de los intereses espurios y venales, con los que el mundo de la "alta cultura" no debía mezclarse. Ya en 1931, a poco de la fundación del CLES capitalino y a pesar de integrar el grupo inicial, Carlos Ibarguren había renunciado públicamente a la entidad por considerar que se trataba de una institución de "simpatizantes del comunismo" (Neiburg, 1998, p. 142). Estas declaraciones, impregnadas del rechazo hacia la cultura de izquierdas, eran en parte coherentes con una de las principales máximas elaboradas por la institución que, acordando con el horizonte de la sociabilidad moderna, excluía el tratamiento de la política dentro de sus aulas.

El fenómeno social y político del peronismo funcionaría, en este sentido, como una suerte de momento bisagra. Según ha entendido Federico Neiburg (1998), el espacio construido por el Colegio buscó dialogar y debatir con interlocutores específicos del campo cultural -la intelectualidad antirreformista- y con actores de la escena política, aunque las formas en las que estos intercambios tuvieron lugar variaron en el tiempo. En este sentido, la irrupción del movimiento peronista en 1945 habría abierto un paréntesis en las prácticas de la entidad que se habría extendido hasta el derrocamiento de Juan Domingo Perón en 1955 y en el cual ella se habría convertido, tácitamente, en un espacio de agregación y vinculación de la intelectualidad opositora. Esta afirmación, usualmente difundida y pasible de ser sostenida, ${ }^{13}$ podría aceptar cierta complejización y ello puede observarse más claramente a partir de una mirada que integre distintas escalas de análisis. ${ }^{14}$ Aun cuando varios de sus miembros eran

\footnotetext{
$12 \mathrm{El}$ acceso a los datos de los socios y su análisis cruzado con los de otras instituciones sociales, profesionales y recreativas permite elaborar un perfil bastante definido de estos grupos de clase media que, sin desmedro de diferir en sus sensibilidades políticas, sostenían prácticas compartidas de inserción múltiple en espacios de la sociedad civil y se consolidaron, hacia mediados del siglo XX, como la élite local. Ver: López Pascual (2016a).

${ }^{13}$ En febrero de 1946, en el contexto proselitista, el Colegio Libre de Buenos Aires ofreció una comida en honor de los miembros de su consejo directivo, secretarios de filiales del interior y asociados a quienes los distintos partidos democráticos habían proclamado sus candidatos a las funciones electivas: José P. Tamborini, Alejandro Ceballos, Juan José Díaz Arana, Rómulo M. Etcheverry, Arturo Frondizi, Américo Ghioldi, Roberto F. Giusti, Eusebio Gómez, Pablo Lejarraga, Julio A. Noble, N. G. Rava, Ricardo M. Ortiz, Nerio Rojas y Esteban F. Rondanina.

${ }^{14}$ En este mismo sentido, Claudio Belini (2018) ha señalado recientemente que el análisis del tratamiento dado por el CLES a los debates en torno a la economía argentina también indicaría una mayor complejidad, atendiendo a las
} 
reconocidos antagonistas partidarios, como fue el caso de Pablo Lejarraga y varios de los disertantes, la tónica general de las actividades del Colegio evitaba manifestar los posicionamientos ideológicos coyunturales y, en cambio, recurría a estrategias metafóricas y elusivas ligadas específicamente a la tarea intelectual, tales como referir a figuras del pasado decimonónico argentino y a la tradición liberal. ${ }^{15}$

Sin embargo, las acciones discretas y sutiles debieron mantener un código de lectura común entre el público, que observaba críticas apropiadas al oficialismo en la selección de temas y conferenciantes. Así lo ponía de manifiesto uno de los asistentes que escribió a la secretaría del Colegio para felicitar a la entidad por el curso dictado por José P. Barreiro celebrando -con una prosa tan abigarrada como visceral y agresiva- que existieran en el país seres humanos "heroicos", "dispuestos a escupir verdades", "nadando en un mar de bestias", cuyas conciencias "cloroformadas por el poderoso anestésico económico" posibilitaban la "gritería inmunda de un rebaño de imbéciles" ${ }^{16}$ El programa cultural se leía, en este contexto, enlazado en la interpretación compleja y conflictiva del fenómeno justicialista, en el que los sectores profesionales de la clase media caracterizaron a los seguidores peronistas como una masa ignorante y violenta, representación social que sustentaba la descalificación de sus opciones políticas (López Pascual, 2019b).

El 17 de julio de 1952, los cursos en Capital Federal fueron suspendidos por la oficina de Reuniones Públicas de la Policía Federal, ${ }^{17}$ lo que permite sospechar que, en el momento en que las prácticas gubernamentales destinadas a censurar a la oposición intelectual se volvieron más frecuentes (Fiorucci, 2011), la dirigencia justicialista se volvió más sensible a las indirectas declaraciones veladas que circulaban en la entidad. En noviembre del mismo año, la situación del organismo central se complejizó en virtud de la explicitación de los conflictos internos que desembocaron en la renuncia de Ricardo M. Ortiz, Homero B. de Magalhaes y Jorge Thénon a sus cargos en el Consejo Directivo. Mediante una larga nota de dimisión en la que la figura del malogrado Aníbal Ponce funcionaba como una pauta de evaluación de lo realizado, quienes se retiraban expusieron críticas muy severas a la gestión del CLES en torno a la planificación de su política cultural, al manejo de los fondos financieros, a las posiciones ideológicas adoptadas y a los hábitos de "renovación mecánica" de autoridades entre los cuales el carácter de vitalicio del cargo de secretario constituía, a su entender, un "defecto fundamental” y un

\footnotetext{
diferencias que se observan en lo referente a la composición de los cuerpos profesionales, del abordaje de los temas y de las lógicas disciplinares que se evidencian entre 1940 y 1950.

${ }^{15}$ Fueron frecuentes las manifestaciones en torno a la figura de Juan Manuel de Rosas, "el tirano", o a las de Bernardino Rivadavia y Esteban Echeverría (López Pascual, 2016a). Sobre el recurso a la disputa por el relato histórico de la nación como estrategia en la cultura de izquierda puede verse Altamirano (2001). Para el caso local, véase Cernadas (2013a)

${ }^{16}$ Fernando Maglia a Pablo Lejarraga, Bahía Blanca, 29 de noviembre de 1949. APL-UNS, Correspondencia.

${ }_{17}$ La actividad del CLES capitalino se desarrollaba en las salas de la Sociedad Científica Argentina, que fue clausurada.
} 
elemento profundamente antidemocrático. ${ }^{18}$ Lo que se manifestó, en primera instancia, como una impugnación de las prácticas institucionales internas constituyó una de las variantes en la disgregación del consenso intelectual opositor como consecuencia del realineamiento de los intelectuales comunistas en torno al antifascismo, a los postulados soviéticos y, en último plano, al mismo peronismo. ${ }^{19}$

En la filial de Bahía Blanca las actividades continuaron sin interrupciones, al igual que en la sede de Rosario, ${ }^{20}$ pero el local céntrico que alquilaban les fue expropiado y cedido a la Confederación General del Trabajo en un acto que, además de sus consecuencias prácticas, tuvo mucho de simbólico toda vez que también expulsaba del solar a la Asociación Empleados de la Administración de la Justicia y su biblioteca pública, a varios centros de estudiantes y a la Federación Universitaria del Sur. La desocupación de ese espacio ya había sido solicitada en 1951 por el gobierno provincial a través del Subsecretario de Cultura José Cafasso, con el objetivo de instalar en esa finca el Conservatorio de Música y Arte Escénico que la dependencia proyectaba crear a la brevedad, ${ }^{21}$ a lo que el CLES se había negado. En marzo de 1952, en lo que la prensa calificó como "una medida apresurada" y "discutible desde el punto de vista legal y constitucional", ${ }^{22}$ la central gremial desplazó al Colegio Libre, ${ }^{23}$ que, desde ese momento, realizó todos sus actos públicos en las salas de la Asociación Bernardino Rivadavia, previo aviso de cada una de sus reuniones a la seccional segunda de la policía federal. Incluso ante estos hechos, las fuentes públicas y privadas de la filial mantuvieron un claro silencio ante lo que empezaba a experimentarse como un clima de obstaculización a la organización y sus actividades por parte del gobierno peronista. Como se ha visto, los hechos de septiembre de 1955 habilitaron toda una serie de declaraciones y posicionamientos categóricos ${ }^{24}$ que, de manera retroactiva, hilvanaban el acontecer institucional de los años anteriores a las manifestaciones y movilizaciones de oposición declarada al justicialismo por "tirano", "déspota" y "demagógico". El CLES capitalino reabrió sus puertas, pero las demás filiales no se reactivaron; desde entonces, y hasta el final de su trayectoria, la estructura del Colegio se circunscribió a la sede porteña, la rosarina ${ }^{25}$ y la bahiense, a causa de las dificultades para mantener y administrar los cuerpos docentes estables en otras filiales. A partir de entonces, el

\footnotetext{
${ }^{18}$ Cursos y conferencias, Buenos Aires, Año XXI, Vol. XLII, enero a marzo de 1953, pp. 545-551. Ortiz, Magalhaes y Thénon, junto a Emilio Troise, Héctor Agosti y María Rosa Oliver crearon, ese mismo año, “La Casa de la Cultura Argentina" que sostuvo una orientación ideológica de tipo comunista (Petra, 2017).

${ }^{19}$ Los comunistas se habrían alejado también de la Sociedad Argentina de Escritores, presidida en ese momento por Carlos Alberto Erro (Prado Acosta, 2013).

${ }^{20}$ Respecto de las diferencias en la dinámica de trabajo de ambas filiales, véase Neiburg (1998).

${ }^{21}$ Véase la correspondencia del Colegio Libre de Estudios Superiores, 5/05/1951, APL-UNS.

22 Democracia, Año XXI, N 5669, Bahía Blanca, 21 de marzo de 1952, p. 4.

${ }^{23}$ Cursos y Conferencias, Buenos Aires, Año XXI, Vol. XLI, №s 241-242-243, abril a mayo de 1952, pp. 102-103, Vida del Colegio.

${ }^{24}$ Resulta particularmente ilustrativo de este punto el discurso pronunciado por Roberto Giusti en septiembre de 1955, con motivo de la reapertura de las actividades del Colegio. Cursos y Conferencias, Buenos Aires, Año XXIV, Vol. XLVII, № 270, septiembre de 1955, pp. 260-261.

${ }^{25}$ Sus principales referentes fueron Olga Cossettini, Cortés Pla y Horacio Thedy.
} 
grupo capitalino estimularía el fortalecimiento de las redes institucionales con otras entidades que permitieran canalizar la extensión de sus actividades mediante el envío de profesores (CLES, 1953, p. 10).

El análisis de estas relaciones entre políticas culturales y dimensiones partidarias puede incluir, asimismo, cuestiones que aluden más específicamente a las problemáticas del campo cultural. Como es sabido, la intelectualidad liberal sostenía una larga tradición en la que asignaba objetivos democratizantes a la circulación y el consumo de productos culturales. El conocimiento sistemático y la difusión de saberes específicos se entendían, de hecho, como vías de constitución de la ciudadanía y de consolidación de lo republicano, del progreso y, de manera global, de la nación. En el caso de la militancia de izquierdas, además, esto adquiría sentidos de transformación social y económica posibles, en mayor o menor grado, a partir de la educación de los sectores menos favorecidos gestionando su acceso a la lectura y los acervos de bibliotecas populares, organizando conferencias, presentaciones teatrales y musicales y publicando periódicos. ${ }^{26} \mathrm{El}$ ascenso de Juan Domingo Perón a la presidencia conllevó, en ese aspecto, el desarrollo de políticas públicas que, en cierta forma -casi como en la dimensión gremial-, disputaban a la cultura socialista el sujeto destinatario de sus prácticas culturales a la vez que convertían a la producción simbólica en asunto de Estado. Este proceso -simultáneo pero heterogéneo en sus escalas nacional, provincial y local- significó desde la conformación de organismos oficiales dedicados a la gestión (Fiorucci, 2008; López Pascual, 2016a) y la creación de cuerpos colegiados de decisión, financiamiento y evaluación, hasta la apertura de entidades educativas de diverso tenor, orientadas a capacitar obreros y calificarlos según las necesidades de la proyectada industrialización, tal como fue el caso de la Universidad Obrera Nacional o, a nivel local, el Instituto Tecnológico del Sur inaugurado en 1947.27 Aunque, como veremos a continuación, la sociedad civil local llevaba décadas reclamando la estructuración de un espacio de educación superior en Bahía Blanca y, en ese sentido, la iniciativa fue celebrada, en la práctica esto supuso una relativa tensión, toda vez que el Estado seleccionaba y jerarquizaba unos saberes, contenidos y docentes en función de una planificación ligada a las nociones de justicia social e industrialización. En verdad, algunos sectores abrazaron las propuestas del Estado y ocuparon espacios en ellas, lo que también permitió que ciertos gestores locales -Julio César Avanza, Miguel López Francés, José Cafasso- adquirieran relevancia en la gestión cultural bonaerense, ${ }^{28}$ mientras que otros las miraron con recelo y distancia, tanto por su ligazón política como por la competencia que generaba en torno a los capitales simbólicos específicos, las concepciones en torno a lo cultural y su posible público, así como las diferencias en cuanto a la condición profesional del trabajo intelectual.

\footnotetext{
${ }^{26}$ Sobre las formas en las que el socialismo organizó y entendió su política cultural desde inicios del siglo XX pueden verse Martocci (2015); Martocci y Laguarda (2017). Para el caso bahiense, se pueden consultar Cimatti (2001) y Bevilacqua (2012).

${ }^{27}$ Sobre el ITS puede verse Marcilese (2006), López Pascual (2016a).

${ }^{28}$ Sobre los lazos entre el asociacionismo cultural local y la gestión peronista bonaerense, veáse López Pascual (2016a).
} 
En la dimensión local, el Colegio resultó un espacio convocante para todo el arco social del Partido Socialista ${ }^{29}$ y, como se verá luego, también albergó a las distintas facciones ideológicas que surgieron en su interior. Aunque el perfil social de sus militantes y dirigentes estaba cambiando y comenzaba a percibirse el acercamiento y la ocupación de espacios por parte de los abogados -como Lejarraga, Juan Félix y Julio César Martella, Américo Malla, Juan Guido Pastorino, Elicena Fernández, Francisco Muñiz o Serafín Groppa- para los años 40 era la figura de Agustín de Arrieta en la que se concentraban, en verdad, la legitimación por la trayectoria política y la constatación del ascenso social habilitado por el acceso al conocimiento y la actividad intelectual. De origen español y formación autodidacta, su desempeño como tipógrafo había permitido a Arrieta el contacto con el mundo editorial, posibilitándole luego la organización y la dirección de periódicos y la construcción de un rol de liderazgo dentro del partido. Simultáneamente, su accionar constante dentro de la sociedad civil local le reportaba un variado y nutrido capital social y lo ubicaba como una figura de referencia cultural, ideológica e inclusive moral. Sin mayores credenciales que esas, su participación en el Colegio se produjo desde el inicio tanto en los espacios directivos como en las salas de conferencias y, además de sus funciones en el órgano Consultivo, intervino en cursillos sobre la realidad local en los que desplegó sus reflexiones en torno a la situación de la ciudad en el contexto patagónico (López Pascual, 2013b). Estas actuaciones, de ninguna manera aisladas, se articulaban con el eje específico de la cuestión regional, en el que tanto la intelectualidad bahiense como el programa general del CLES tenían objetivos y cifraban esperanzas.

\section{La dimensión regional como eje de trabajo}

Y es que, como ya hemos analizado, desde inicios del siglo XIX circulaban proyectos, ideas y propuestas que postulaban la centralidad de Bahía Blanca en el ordenamiento de un territorio que, con delimitaciones variables, se entendía como "la Patagonia". Desde entonces y hasta

\footnotetext{
${ }^{29}$ En Bahía Blanca, el socialismo constituía una fuerza política que se estaba transformando internamente y consolidaba su posición frente a otras. Originado a partir de la movilización de sectores de trabajadores inmigrantes a fines del siglo XIX, su perfil social se ampliaba y complejizaba a la par de la variación de la estructura social de la localidad, incorporando así a las capas de profesionales universitarios que se instalaron en la ciudad desde inicios de la última centuria. En este sentido, y en el contexto de fraudes y abstenciones electorales, el Partido había accedido al gobierno municipal entre 1932 y 1935, a través de la figura del obrero gráfico Agustín de Arrieta, quien lideró un relativo mejoramiento de las condiciones de vida de los vecinos y de la ciudad y abrió el acceso de las clases trabajadoras al Concejo Deliberante (Cernadas, 2013). A partir de los estudios de Gonzalo Cabezas (2013), sabemos que, para la década de 1920, el perfil sociodemográfico del Centro Socialista de Bahía Blanca se presentaba como mayoritariamente masculino, argentino y con alta cohesión de vínculos familiares; preponderaban los trabajadores manuales (sobre todo conductores de carruajes y oficios relacionados con la construcción) y los empleados de comercio y su dispersión habitacional se concentraba principalmente en la zona macrocéntrica. Resulta interesante observar que, de acuerdo a lo analizado por Camarero y Herrera (2005), la ampliación de las filas partidarias y la incorporación de grupos universitarios e intelectuales fue un proceso general del Partido, como consecuencia de la crisis de 1930. Asimismo, de acuerdo a lo observado por Agesta (2016), en los espacios asociativos de Bahía Blanca, desde inicios del siglo XX, se registró una paulatina transformación en el perfil de sus miembros, con una creciente presencia de quienes ejercían profesiones liberales como la abogacía o la medicina.
} 
mediados de los años 50, cuando la provincialización de los Territorios Nacionales de La Pampa y Río Negro los volvió inviables, diversos planes de centralización administrativa de la ciudad a partir de la configuración de un nuevo estado circularon en la prensa, generando consenso en la opinión pública y obteniendo apoyos políticos variables entre los poderes nacionales. El pensamiento en torno a la región, asimismo, contempló también desarrollos infraestructurales que organizaban la producción agraria y frutihortícola de la zona dirigiendo su desplazamiento confluente y concentrándola en el puerto de Ingeniero Whitey que pretendían conectar la ciudad con el resto de la Norpatagonia y algunas localidades portuarias chilenas. ${ }^{30}$ De manera concomitante, el crecimiento demográfico y la complejización que derivaron de los procesos de modernización y masificación social durante la primera mitad del siglo XX dieron bases a una intensa movilización ciudadana que elaboró y reclamó por la constitución de entidades de educación superior radicadas en Bahía Blanca, atendiendo a su consolidación como "centro de irradiación cultural" del sur argentino (López Pascual, 2017).

Aunque estas aspiraciones de hegemonía se desprendían, en buena medida, de las ambiciones de una heterogénea burguesía local que procuraba disputar la centralidad material y simbólica a la ciudad de Buenos Aires, también es posible rastrear algunas de estas imágenes en proyectos originados en otras esferas. En efecto, el Colegio Libre asentó su programa de acción en planteos que incluían muy claramente el pensamiento sobre la región, en diversas dimensiones. En primer lugar, desde su Cátedra Lisandro de la Torre buscó intervenir en el debate general en torno a las políticas económicas (Belini, 2019) y ello asumió especial interés en la ciudad, donde la figura de Ricardo M. Ortiz fue fundamental. Como ya hemos visto, su análisis enfocado en resolver la centralización de las actividades de exportación e importación en el puerto de Buenos Aires -con la consecuente necesidad de transportar las mercancías desde y hacia el resto del país- conducía a una reflexión sobre la infraestructura portuaria de Bahía Blanca. A su criterio, la solución estribaba en convertirla en un puerto nacional importador conectado con su propio hinterland y, también, con los puertos de menor envergadura que debían desarrollarse a lo largo de la costa patagónica. ${ }^{31}$

Por otra parte, y aun adoptando la noción de la tarea cultural como misión civilizatoria, ese horizonte se desplazó y modificó al hacerlo converger con lo latinoamericano. El Viejo Mundo continuó funcionando como un punto de referencia que, sin embargo, comenzaba a complejizarse, no solo por la revisión nacionalista heredada del Centenario y la recepción de los diversos movimientos de vanguardia, sino también a partir de las experiencias autoritarias frente a las que las alianzas de intelectuales y las políticas culturales funcionaron como

\footnotetext{
${ }^{30}$ Si bien el ideólogo más reconocido de estos planes fue el artista plástico e ingeniero Domingo Pronsato, las iniciativas suscitaron amplios debates en los que se involucraron buena parte de las corporaciones locales, los poderes políticos provinciales y territorianos y algunos legisladores y dirigentes nacionales. Sobre estos aspectos puede consultarse Silva et al. (1972).

${ }^{31}$ Un análisis acerca del pensamiento de Ricardo M. Ortiz sobre Bahía Blanca y su región aledaña puede consultarse en López Pascual (2016b).
} 
estrategias de acción política e ideológica de la resistance antifascista. A su vez, América comenzó a entenderse como el lugar de la identidad y de "lo local", recuperando así la trayectoria crítica de la Reforma y los debates de la vanguardia estética respecto a la modernidad nacional que, a partir de la segunda posguerra, se articularían de maneras novedosas con los enunciados antiimperialistas. Según lo formulado por Luis Reissig, la política de los países de este continente debía orientarse a construir la "nación" - diferente a país o Estado- a través del reagrupamiento de los individuos en un plano social equivalente, igualitario.

Una política a la cual debemos aplicarnos, de preferencia, es la del desarrollo de esa
conciencia nacional, a partir de la cual puede pensarse en la formación de una conciencia
continental. Términos los dos que se suceden y complementan, pues por naturaleza,
América es una e indivisible.
Cómo la cultura puede y debe colaborar en la formación de esa conciencia nacional, complemento de
la americana, lo llevamos en parte dicho: el conocimiento de la realidad nacional y sus problemas
(...)
Precisamente, lo que se persigue a través de la idea de crear en cada país una escuela u
organización de estudios nacionales, es contribuir a democratizar la conciencia social y
económica, de modo tal que no resulte como hasta ahora que esos temas son solamente
conciencia de unos privilegiados. Y esa obra es función de Universidad y función de
pueblo. ${ }^{32}$

La argumentación incluía -y legitimaba- las actividades del CLES no solo como herederas y superadoras del Manifiesto Liminar, sino también como indispensables para la concreción del proyecto global americano: "la consigna cultural debe ser: articular, articular, articular. Articular en una América indivisible".33 En ese plan continental, resultaba menester el entendimiento de las heterogéneas problemáticas de cada espacio y ello condujo a estimular estudios específicos. Mientras la sede santiagueña funcionaba como una suerte de espacio universitario y se profundizaba sobre las especificidades del problema del agua (Guzmán, 2014), la filial de Bahía Blanca era definida por su rol fundamental como espacio dinamizador de los territorios australes, coincidiendo así con parte de las aspiraciones locales, pero también, en una dimensión más concreta, enviando publicaciones y manteniendo contactos con grupos letrados de otras provincias y países latinoamericanos. ${ }^{34}$

En ese sentido, la dirigencia porteña manifestó la voluntad de continuar la expansión geográfica del Colegio incorporando a "todos aquellos hombres y mujeres de la Patagonia, el Neuquén, del sur de la Provincia de Buenos Aires y de La Pampa que tienen a Bahía Blanca como capital natural". Desde esa perspectiva, los bahienses debían empeñarse en establecer

\footnotetext{
${ }^{32}$ Cursos y conferencias, № 138, septiembre 1943, Año XII, Volumen XXIII, p. 504. Resaltado en la fuente.

${ }^{33}$ Cursos y conferencias, № 138, septiembre 1943, Año XII, Volumen XXIII, p. 508. Resaltado en la fuente.

${ }^{34}$ En efecto, durante los años en que la central del CLES estuvo clausurada, la filial Bahía Blanca publicó un boletín local denominado Páginas que remitía, entre otros destinatarios, a bibliotecas en La Habana. APL-UNS. Lamentablemente, esta publicación no se ha conservado, por lo que su estudio resulta dificultoso.
} 
comunicaciones con "todos los centros poblados" de esos lugares aprovechando que contaban con "mejores condiciones que los de Buenos Aires" para hacerlo, en virtud de la distancia y del conocimiento personal, con la finalidad de que cada Territorio Nacional organizara una filial y que cada ciudad "importante" contara con sus cátedras. ${ }^{35}$ En función de estas premisas, la dispersión espacial y una apropiada conexión con personalidades cuyas ideologías fueran afines al trabajo del Colegio constituyeron aspectos siempre presentes en la correspondencia entre Reissig y Lejarraga, y es probable que las grandes dimensiones territoriales de la provincia de Buenos Aires hayan incidido en la distribución regional tentativa que la entidad central buscó establecer entre las sedes en 1942. Mientras a la filial de Bahía Blanca le correspondía trabajar en la zona comprendida entre las poblaciones de Coronel Dorrego, Coronel Pringles, Lamadrid, Coronel Suárez y Puán, su par de Mar del Plata se ocuparía de las localidades de Madariaga, Necochea, Maipú y Tandil, en tanto una posible sede de Tres Arroyos cubriría el espacio de Benito Juárez, Olavarría y Laprida. La entidad platense, en colaboración con la de la Capital Federal, quedaría a cargo de las ciudades restantes. Como se ha visto más arriba, esta proyección resultó inadecuada en términos económicos y administrativos y, hacia la mitad de la década de 1950, fue reformulada, sin desprenderse de su voluntad de circulación territorial, pero anclando en las infraestructuras institucionales ya desarrolladas en otras provincias.

Si desde Buenos Aires se pensó la política cultural del CLES como la punta de lanza en el avance civilizatorio hacia el sur, la sociedad civil local lo concibió como la refrenda a sus intenciones y como un paso hacia adelante en la demanda de contar con una universidad nacional. ${ }^{36}$ En verdad, las relaciones con los organismos culturales municipales no fueron constantes ni fluidas, toda vez que dependencias como la Comisión Municipal de Cultura y la Subsecretaría de Cultura y Acción social -a la sazón, recientemente creadas y en proceso de consolidación- fueron observadas como entidades demasiado ligadas a los grupos nacionalistas y al peronismo de cuño forjista. ${ }^{37}$ No obstante, la variable de la cultura y su institucionalización en la región funcionaba -a diferencia de otros espacios, en los que constituía el meollo de los procesos de definición identitaria (Lanzillotta, 2016; Salomón Tarquini, 2016) - como una síntesis de los planes de centralización y consolidación del poder simbólico a partir de ocupar un lugar preponderante en la producción y la circulación del conocimiento. En este sentido, los eventos de septiembre de 1955 no solo significaron el inicio de normalizaciones modernizadoras en universidades ya consagradas, ${ }^{38}$ sino que abrieron la

\footnotetext{
${ }^{35}$ Cursos y Conferencias, Año X, Volumen XX, №s 7, 8 y 9, Octubre, Noviembre y Diciembre de 1941, pp. 986-990. Reproducción de la carta enviada por Luis Reissig con motivo del inicio de las actividades en p. 988.

${ }^{36}$ Un análisis detenido de la agenda de trabajo ampliada del CLESBB y sus interacciones con el asociacionismo cultural y la prensa local ha sido incluido en López Pascual (2016a).

${ }^{37}$ Una reconstrucción del proceso de oficialización de las tareas culturales en Bahía Blanca durante el período en cuestión puede encontrarse en López Pascual (2016a).

38 Sobre el proceso de intervención y normalización de la Universidad de Buenos Aires, puede verse Suasnábar (2004).
} 
puerta al inicio del proceso local que originó la Universidad Nacional del Sur un par de meses más tarde ${ }^{39} \mathrm{y}$, a la vez, dio comienzo al declive de los consensos opositores. Como se sabe, las interpretaciones acerca del fenómeno peronista y las reflexiones acerca de qué hacer con sus seguidores fracturaron profundamente a la coalición opositora e, inclusive, trazaron grietas complejas en los partidos liberales como el Socialista (Tortti, 2009; Ferreyra, 2010) o la Unión Cívica Radical (Spinelli, 2005), coincidiendo, en parte, con lo que habían anticipado la "crisis Real" al interior del Partido Comunista en 1952 (Petra, 2017) y la apertura de la línea de Acción Socialista, liderada por Dardo Cúneo (Herrera, 2013)..$^{40}$ Las derivas de estas redefiniciones dialogaron estrechamente con el reposicionamiento de estos gestores, particularmente en el caso de Lejarraga, que quedó vinculado a la línea más renovadora del Partido Socialista, ${ }^{41}$ y con la determinación de nuevas políticas culturales, esta vez, legitimadas por la naturaleza estatal de la nueva Universidad.

Desde la campaña popular promovida por la Federación Universitaria del Sur en octubre de 1955, el Colegio Libre participó directamente en las asambleas convocadas a fin de lograr la creación de la Universidad Nacional del Sur, enviando a Pablo Lejarraga, Federico Baeza y Moisés Grodsinsky como delegados institucionales. De allí que el mismo Lejarraga integrara la comisión que, en diciembre del mismo año, se reunió con las autoridades nacionales y concretó la ansiada constitución en enero del año siguiente (Orbe, 2007a). Desde su creación, la novel Universidad, su Departamento de Humanidades y la Dirección de Extensión Cultural (DEC) fueron espacios y elementos catalizadores de la transformación cualitativa de los debates intelectuales, a la vez que modificaron definitivamente las estrategias implementadas hasta entonces por los agentes del campo cultural bahiense. La cercanía y el trabajo conjunto con el CLES continuaron, asimismo, tanto durante los momentos de organización efectiva de la casa de altos estudios -en la que un rol importante lo ocupó la poeta y docente Berta Gastañaga-42 como en el desarrollo posterior de la institucionalidad, teniendo en cuenta que

\footnotetext{
39 En efecto, la interrupción del gobierno de Juan Domingo Perón en septiembre de 1955 tuvo importantes consecuencias en el mundo cultural de Bahía Blanca; en el mismo mes el ITS fue intervenido por el Comando Naval de Bahía Blanca, a la vez que el Ministro de educación de la "Revolución Libertadora" delegó el estudio de su reestructuración institucional a un grupo conformado por Vicente Fatone, Benjamín Villegas Basavilbaso, Eduardo Braun Menéndez, Ezequiel Martínez Estrada y Manuel Villada Achával. Simultáneamente, la movilización popular local que, durante dos décadas había sostenido el interés en la creación de una casa de altos estudios, adoptó la forma de una "comisión pro-Universidad del Sur". En enero de 1956, estos itinerarios concluyeron con la creación de la Universidad Nacional del Sur (Orbe, 2007).

${ }^{40}$ La propuesta de organización lanzada por Cúneo a partir de la publicación de Acción Socialista fue rápidamente recepcionada en Bahía Blanca, donde algunos jóvenes que ya lideraban la Federación Universitaria del Sur crearon en agosto de 1954 la Seccional Bahía Blanca de la Federación Regional del Sur de Acción Socialista, nombrando a Julio N. Abelleira como su secretario general (Archivo APL- UNS).

${ }^{41}$ Como ha reconstruido Silvana Ferreyra (2010), las viejas tensiones internas del Partido Socialista se reeditaron y profundizaron a causa de los posicionamientos frente al peronismo distinguiéndose, primero informalmente y luego de manera institucional, entre los ghioldistas y los renovadores, representados desde 1956 por el historiador José Luis Romero. A estos últimos se alinearon buena parte de los socialistas bahienses, como Pablo Lejarraga, Américo A. Malla y Francisco G. Muñiz.

${ }^{42}$ Profesora en Letras y poeta, Berta Gastañaga había sido convocada para integrar las primeras comisiones del CLES bahiense. Allí conoció a Pablo Lejarraga, con quien luego formó una familia.
} 
Gregorio Scheines ${ }^{43}$ fue designado como director de la DEC. Allí, se propulsó una agenda de trabajo que no solo retomaba y proseguía las formas y objetivos instalados por el Colegio en materia de desarrollo regional e interés por lo latinoamericano, sino que también, en no pocos casos, ambas entidades funcionaban de manera coordinada y compartiendo esfuerzos. En este sentido, asignaron especial interés al trabajo con Ezequiel Martínez Estrada -residente en Bahía Blanca desde 1949- y con Ricardo M. Ortiz, ${ }^{44}$ así como al movimiento estudiantil (López Pascual, 2015). Ello visibilizó la adopción de un posicionamiento ideológico que, en buena medida, operaría como gesto de disidencia crítica frente al delineamiento de posturas acendradamente antiperonistas y se acompañaría, en el caso de Lejarraga, por su vinculación a las filas del Partido Socialista Argentino.45

La discusión en torno a las políticas culturales, sus objetivos, el rol del Estado y los privados entró en un nuevo período de su historia a partir de estos años, toda vez que, en el mismo magma agitado y dinámico, se generaron las disputas en torno a la educación "libre" 46 y se profundizaron las divisiones en la cultura de izquierdas a partir de la definición de facciones más radicalizadas que cuestionaron las trayectorias de sus padres intelectuales y políticos a partir del prisma revolucionario (Tortti, 2009). ${ }^{47}$ Las tensiones surgidas entre los librepensadores y la generación "parricida", tal como la denominara Jaime Rest en 1960, se pusieron de manifiesto en el mundo del Colegio, como lo atestigua la correspondencia mantenida entre Pablo Lejarraga y Florentino Sanguinetti o el mismo Reissig. Los lineamientos reformistas eran interpelados por la aparición de nuevas formas de intervención intelectual que, como sabemos, ${ }^{48}$ revisaban esos presupuestos a la luz de las interpretaciones revolucionarias y de las fisuras en el pensamiento de los primeros a raíz de la revisión del sentido del peronismo, del debate "laica o libre" y de las formas de entender el nacionalismo

\footnotetext{
${ }^{43}$ Abogado, escritor, docente y gestor, Scheines integró numerosas entidades culturales -entre ellas, el CLES- en carácter de dirigente. Desde 1956 y hasta mediados de la década de 1980, se desempeñó como director del Departamento de Extensión Cultural de la Universidad Nacional del Sur. Sobre esta gestión y sus interacciones con el Colegio Libre y otros agentes del campo cultural, puede verse López Pascual (2019a).

${ }^{44}$ El acompañamiento a la gestión de Ricardo M. Ortiz se produjo desde lo institucional, a pesar de los reparos con que Lejarraga y otros le observaban: "Ortiz es candidato estudiantil y de un grupo de profesores al Rectorado de la Universidad del Sur. Le debo adelantar que lo ambiciona y está esperanzado. Aparte de su capacidad, y su vinculación intelectual con el Sur, no me parece que en este momento le convenga a la Universidad. Me dijo Giusti que además es un poco rígido, personalista, y que no sería de extrañar que los muchachos se llevaran una sorpresa." Pablo Lejarraga a Luis Reissig, 12 de junio de 1958. APL-UNS.

${ }^{45}$ En la fractura interna que sufre el PS en 1958, Lejarraga se alinea con el liderazgo de Alfredo Palacios y desplaza su militancia hacia el PSA, desempeñándose como Diputado Nacional.

${ }^{46}$ Usualmente conocido como el debate "laica o libre", nos referimos aquí a los enfrentamientos que se suscitaron ante la posibilidad de que una reformulación del marco legal eliminara el monopolio estatal sobre la educación superior, abriendo la puerta a las iniciativas privadas, principalmente religiosas (Suasnábar, 2004).

${ }^{47}$ Para el caso bahiense puede verse Orbe (2007b) y López Pascual (2013b).

${ }^{48}$ Nos referimos aquí a las fracturas que se observaron en el campo cultural a partir de la relectura del fenómeno peronista, particularmente aquellas que tocaron el escenario del progresismo y la cultura de izquierdas, como el alejamiento de la generación "contornista" de los círculos de Sur. Sobre esto puede consultarse Altamirano (2001). Terán (1991) y Sigal (2002).
} 
y el antiimperialismo. ${ }^{49}$ Asimismo, los cuestionamientos ideológicos en torno al sentido de la cultura y el problema de la nación se acompañaban de las dificultades que encontraba el CLES para obtener colaboraciones significativas, toda vez que quienes solían hacerlo se comprometían, de manera creciente, con el desarrollo de una diversidad de emprendimientos en los que encontraban espacio laboral: periódicos, universidades, editoriales y organismos estatales. En la escala local, la filial Bahía Blanca recibió entre 1958 y 1959 un considerable número de renuncias a la membresía, y Lejarraga manifestaba con claridad su preocupación ante la posibilidad de que el Colegio "muera o vegete sin pena ni gloria" ${ }^{50}$ En ese sentido, el Colegio Libre entraría en una larga crisis que se profundizó cuando Luis Reissig fue elegido por la presidencia de Arturo Frondizi -integrante del CLES- para acompañar la gestión de Luis R. Mac Kay en la cartera de Educación. A los pocos meses, Reissig dejó el cargo de asesor y se trasladó a Washington, en el contexto de los encendidos debates en torno a las universidades de tipo privado.

La expansión de las posiciones autoritarias y represivas desde mediados de los años 60 profundizó el trance institucional no solo por la persecución sistemática a las ideas libertarias, sino también por la supresión del ejercicio legal de la política decretado por el gobierno de facto de la "Revolución Argentina". La vigilancia policial sobre las actividades del CLES -que continuaron desarrollándose hasta fines de la década, aunque a menor escala-51 se solapó con la impugnación global de las sensibilidades políticas más o menos cercanas al marxismo y la creciente imposición de un Estado que intervenía en la base fundamental del sistema de la educación superior, cual era la autonomía universitaria. ${ }^{52}$ El Colegio, que hasta entonces proveía el capital social que, en buena parte, posibilitaba el desarrollo de muchas de las actividades de extensión de la UNS, también sufrió las pesquisas de la fuerza pública ante lo que ratificó su defensa a la libertad de expresión y su rechazo a la censura. Endurecidas las prácticas coactivas sobre los gestores culturales, las propias entidades comenzaron a efectuar

\footnotetext{
${ }^{49}$ En octubre de 1958, en el contexto de la elección del nuevo rector para la UBA, Sanguinetti escribió: “Malas [noticias], en cambio, con referencia a nuestros problemas universitarios. Querellas, apartamientos, soluciones poco 'reformistas' en estas vísperas electorales. La nómina de 'egresados' de Derecho (Ismael Viñas, Calot, Pedroncini, Stanislavsky), y estudiantes, tienen más o menos el mismo tinte. (...) A raíz de esto han surgido discrepacias y renuncias cuyo alcance todavía no puede precisarse pero sería, en verdad, lamentable cualquier fisura en el frente reformista. Los problemas de mayor proyección continúan confusos y en la zona de los rumores...". APL-UNS.

${ }^{50}$ En junio de 1958, desde Washington, Luis Reissig escribía a Lejarraga: “Comparto su preocupación en cuanto a la necesidad de que el Colegio cumpla el papel que exigen las circunstancias. Para esto hay que preparar un plan, encontrar los colaboradores y dedicar a la tarea mucho entusiasmo y tiempo. En la medida de la concurrencia de este conjunto de factores, así podrá funcionar el Colegio. Pero bien conoce usted -viejo y firme luchador- lo difícil que es lograr esto." APL-UNS.

${ }^{51}$ La merma en las actividades que preocupaba a Reissig y Lejarraga a fines de los 50 se hace particularmente evidente en la documentación institucional posterior a 1961, que se vuelve prácticamente inexistente. La publicación de los eventos en la prensa periódica, por su parte, confirma esta disminución en la vitalidad, que se registra durante la última década de existencia.

52 En 1966, el Poder Ejecutivo intervino las Universidades Nacionales, creando así un conficto de profundas consecuencias en el mundo universitario cuyo hito más recordado es la "Noche de los Bastones Largos" (Suasnábar, 2004).
} 
procesos de autocontrol y vigilancia sobre sus miembros, ${ }^{53}$ sus actividades y sus manifestaciones, toda vez que las relaciones dialogadas entre cultura y política devinieron progresivamente imposibles.

Asimismo, la emergencia y visibilización de nuevos actores políticos e intelectuales pusieron en entredicho la hegemonía de la mirada liberal y reformista sobre la acción cultural y lanzaron interpelaciones que abrevaban en lógicas distintas y que, desde entonces y hasta el final del período, movilizarían otras prácticas simbólicas. En efecto, en diversos espacios aparecieron las propuestas que se encabalgaban, de lleno, en la discusión relativa a las relaciones entre la cultura y la revolución, emanadas de la difusión del ideario radicalizado entre los estudiantes y los agentes de la cultura. La tarea cultural entendida en clave de "extensión" o "irradiación" fue crecientemente cuestionada por parte de quienes, observándola como una forma de actitud paternalista, elitista, cosmopolita y unidireccional, proponían reemplazarla por otras que asignarían un lugar primordial a "lo nacional y lo popular" y revisarían lo que hasta entonces se entendía como "alta cultura". ${ }^{44}$ Ese sería el contexto en el que, en diciembre de 1970, el ciclo de existencia del CLES fue cerrado por decisión de una asamblea general extraordinaria que votó su disolución total (Gambini, 2006). Cursos y conferencias, su emblemática revista, había dejado de publicarse diez años antes.

\section{Palabras finales}

El estudio de políticas culturales, y en especial su análisis a partir de reconstrucciones empíricas en las que se vea claramente la multidimensionalidad de la experiencia cotidiana de los sujetos históricos, procura reflexionar sobre el poder de definición, distinción y validación de la producción simbólica. En efecto, estas aproximaciones involucran la consideración sobre la categoría de "lo público" en tanto representación del bien común, universal, lo que constituye un elemento central en la agencia del Estado (Bourdieu, 1993) y, también, en la de heterogéneos grupos sociales que canalizan así sus inquietudes y matrices de pensamiento. Enfoque microanalítico, observación "a ras de suelo", reducción y juego de escalas, perspectiva translocal,55 todos ellos procuran dar cuenta, en definitiva, de la necesidad de pensar los procesos pretéritos atravesados por lógicas multiescalares, de naturaleza y régimen de historicidad diversos y de gravitación desigual. El objeto aquí estudiado, asimismo, presenta vacíos en su inacabada reconstrucción empírica, a la vez que abre muchos interrogantes -algunos de ellos deslizados a lo largo del texto- que restan por ser explorados.

\footnotetext{
${ }^{53}$ El largo entendimiento entre el CLES bahiense y la Asociación Bernardino Rivadavia, donde realizaba sus encuentros, se clausuró a raíz de las tensiones, renuncias y desplantes generadas entre las Comisiones Directivas por intentos de control y censura ideológica por parte de la segunda.

54 Sobre este proceso puede consultarse v.g. Longoni y Mestman (1999); Perez, Lida y Lina (2010) y, para el caso local, Vidal (2016 y 2019).

${ }^{55}$ La propuesta de una microhistoria translocal ha sido sugerida recientemente por De Vito (2015).
} 
En este sentido, el análisis de la experiencia local plantea la posibilidad de proponer una serie de elementos generalizables al devenir de la institución entendida en su perspectiva global.

Como hemos visto, el desarrollo de las políticas culturales durante la segunda posguerra en Argentina implicó el mayor involucramiento de un Estado que -en todas sus escalas- se ampliaba y legislaba su injerencia en áreas que hasta entonces habían sido terreno del accionar de intelectuales y gestores cuyos intereses se vinculaban de maneras disímiles con las estructuras partidarias y económicas. Todos estos escenarios se hallaban atravesados, en mayor o menor medida, por el fin democratizador de la política cultural que, según ha entendido Vincent Dubois (1993), se ha convertido en un mito fundante que -aunque su definición permanezca ambigua- ha legitimado tanto las figuras del intelectual como las acciones estatales.

Si desde fines del siglo XIX la ampliación se había referido a una voluntad de los sectores letrados de difundir la (alta) cultura al "pueblo" en pos de la "civilización", hacia 1918 estos significados comenzaron a expandirse como consecuencia del movimiento reformista iniciado por los universitarios cordobeses, entendiendo el paradigma democrático como el eje de gobierno de las instituciones culturales. En el mismo movimiento político que presionaba por la expansión de los derechos cívicos, se encabalgaban así las demandas por una participación igualitaria, representativa y reglada de todos los actores involucrados en las decisiones que atañían a la cultura del saber. La instalación de las formas locales del Estado de Bienestar durante los años cuarenta del siglo XX profundizó estas nociones al dotarse de espacios, normas y burocracias específicas para dar forma pública a las políticas de expansión del acceso al conocimiento y los bienes simbólicos, a la vez que consolidó las prerrogativas del Estado en la promoción de los productos culturales más populares y masivos, como la radiofonía y, más adelante, la televisión.

El Colegio Libre de Estudios Superiores no fue indiferente a este proceso, toda vez que constituía uno de los espacios en los que se congregaban los sectores librepensadores como forma de gestión de un proyecto intelectual que se distanciaba del corporativo y daba continuidad al reformista, difundiéndolo a partir de una red de filiales en el país. El devenir político internacional de fines de los años '30 estimuló una interpretación de la coyuntura local que decantó en una generalizada distinción y agregación partidaria, autojustificada a partir de la construcción de una imagen de un Otro político y social caracterizado por el autoritarismo y la ignorancia. El saber y el conocimiento, entonces, funcionaron como los ejes mediante los que se buscaba promover el progreso nacional $\mathrm{y}$, de forma simultánea, variables de congregación y distinción de las sensibilidades ideológicas.

Aquí es donde el problema de la escala se vuelve fundamental: en principio, porque desde los espacios centrales se organizaron propuestas que contemplaban todo el territorio en términos ideales, pero que solo cobraban existencia material en el trabajo micro, reducido, de la acción singular en el plano de las ciudades y los pueblos. Pero también, porque esos proyectos "macro" adquirieron connotaciones diferenciales a partir de la imbricación con los 
intereses y las aspiraciones situadas, es decir, aquellas que emergían de las disputas, los consensos y las aspiraciones locales. La imagen de una relación verticalista o estática dentro de un esquema de centro y periferia -que es lo que se suele inferir de una estructura organizativa en filiales o sucursales- acepta matices y abre preguntas. No sugerimos obliterar que, en efecto, los centros administrativos establecen vínculos jerárquicos con los territorios que quedan bajo su jurisdicción; sin embargo, en el caso estudiado, lo que parecía funcionar eran relaciones bilaterales en las que ambas partes -y sus respectivos capitales políticos, sociales y culturales- eran mutuamente necesarias para el funcionamiento de la acción colectiva: si Lejarraga requería de Reissig para contactar oradores y conferencistas "de renombre", Reissig no lograba que el programa del Colegio se difundiera de manera ampliada sin la mediación de los gestores que conocían su región, como el mencionado abogado o la educadora Olga Cossettini.

Finalmente, la cuestión regional se presenta como un tópico y, en simultáneo, ofrece un problema, ya que instala el cuestionamiento acerca de las representaciones espaciales en tanto productos sociales con incidencia directa en las prácticas cotidianas. Si las políticas culturales elaboradas por el CLES, en sus distintas instancias, se proyectaban en un espacio que variaba entre las ciudades y sus zonas de "influencia", las regiones económicamente articuladas y el territorio nacional, no es menos cierto que su horizonte de trabajo se constituía, principalmente por su herencia reformista, en una escala continental y a partir de una mirada que revisaba y discutía las influencias del Viejo Mundo. De una región macro a la mirada micro sobre sujetos específicos, la observación sobre lo político se comprende aquí como el ejercicio cotidiano del poder o, como poéticamente sugiere Jean François Sirinelli, los individuos tejiendo a diario, y por sus propios vínculos, la vida de la Polis.

\section{Referencias Bibliográficas}

Agesta, M. (2014). Entre el asociacionismo cultural y el impulso estatal. Los primeros salones y los intentos de institucionalización de la plástica en Bahía Blanca (1924-1926). VI Jornadas de Historia de la Patagonia. Universidad Nacional del Comahue, Cipolletti.

Agesta, M. (2016). Modernismo de gente de bien. Asociacionismo intelectual y cultura de élite en Bahía Blanca (1882-1930). V Jornadas Nacionales de Historia Social. Red Internacional de Historia Social y Centro de Estudios Históricos "Prof. Carlos Segreti", La Falda.

Agesta, M. y López Pascual, J. (2018). Lecturas para una política de la cultura. En M. Agesta y J. López Pascual (Eds.), Estado del arte. Cultura, sociedad y política en Bahía Blanca. Bahía Blanca: EdiUNS. En prensa.

Altamirano, C. (2001). Peronismo y cultura de izquierda. Buenos Aires: Temas.

Álvarez Lázaro, P. (1999). La Institución Libre de Enseñanza en la tradición del pensamiento masónico europeo. En E. M. Ureña y P. Álvarez Lázaro (Eds.). La actualidad del krausismo en su contexto europeo. Madrid: Universidad Pontificia Comillas- Fundación Duques de Soria y 
Editorial Parteluz. Recuperado de: http://www.colectivoginer.com/htm/lazaro2.pdf [Última Consulta 23/03/2015].

Belini, C. (2018). Una radiografía critica de la economía peronista. El Colegio Libre de Estudios Superiores y los cursos de economía argentina de 1940 y 1950. Acontracorriente, vol. 16 (1), 264-293.

Bevilacqua, R. (2012). La actividad cultural del Partido Socialista. Bahía Blanca a comienzos del siglo XX. Revista de Historia Bonaerense, (39), 105-112.

Bourdieu, P. (1993). Esprits d'État. Genèse et structure du champ bureaucratique. Actes de la Recherche en Sciences Sociales, (96-97), 49-62.

Bourdieu, P. (2002 [1966]). Campo de poder, campo intelectual. Itinerario de un concepto. Buenos Aires: Montressor.

Cabezas, G. (2013). Perfil sociodemográfico del Centro Socialista bahiense y trayectorias biográficas de sus afiliados a comienzos del siglo XX. XIV Jornadas Interescuelas/Departamentos de Historia. Departamento de Historia de la Facultad de Filosofía y Letras- Universidad Nacional de Cuyo, Mendoza.

Caldo, P. y Fernández, S. (2012). La vida como pretexto. Una aproximación a la relación entre biografía e historia a partir del caso de Olga Cossettini, Santa Fe, 1898-1987. Estudios del ISHIR, vol. 2 (4), 175-187.

Camarero, H. y Herrera, C. (2005). El Partido Socialista en Argentina. Sociedad, política e ideas a través de un siglo. Buenos Aires: Prometeo.

Cernadas de Bulnes, M. (1999). La revista Cursos y Conferencias: un proyecto cultural diferente. Cuadernos del Sur, (28), 59-79.

Cernadas de Bulnes, M. (2005). Una propuesta cultural alternativa para la región en la década del cuarenta: el Colegio Libre de Estudios Superiores en Bahía Blanca. En M. Cernadas de Bulnes y M. Vaquero (Comps.), Problemas sociopolíticos y económicos en el Sudoeste Bonaerense. Actas de las Terceras Jornadas Interdisciplinarias del Sudoeste Bonaerense (pp. 27-35). Bahía Blanca: Archivo de la Memoria de la UNS.

Cernadas de Bulnes, M. (2006). El entramado cultural de Buenos Aires desde las páginas de Cursos y Conferencias. En H. E. Biagini y A. A. Roig (Dirs.), El pensamiento alternativo en la Argentina del siglo XX. Tomo II, Obrerismo, vanguardia, justicia social (1930-1960) (pp. 605-618). Buenos Aires: Biblos.

Cernadas de Bulnes, M. y Llull, L. (1997). Intelectuales y compromiso político: el Colegio Libre de Estudios Superiores 1930-1959. VI Jornadas Interescuelas/Departamentos de Historia. Facultad de Ciencias Humanas, Universidad Nacional de La Pampa, Santa Rosa.

Cernadas de Bulnes, M. y Llull, L. (2000). Producción y consumo de una élite intelectual argentina: el Colegio Libre de Estudios Superiores. 1930-1959. En J. Barrull Pelegrí y M. Botargues Palasí (Eds.), Història de la Cultura: Producció cultural i consum social (pp. 395-428). Lleida: Institut d'Estudis Ilerdencs. 
Cernadas, M. (2013a). Nuevos Tiempos: una voz socialista para el Sudoeste bonaerense (19301936). En M. Cernadas y P. Orbe (Comps.), Itinerarios de la prensa: cultura política y representaciones en Bahía Blanca en el siglo XX (pp. 163-188). Bahía Blanca: EdiUNS.

Cernadas, M. (2013b). Cuando los socialistas gobernaron Bahía Blanca: la intendencia de Agustín de Arrieta (1932-1935) y el desafío de transformar la cultura política "criolla". Estudios Sociales, (44), 101-122.

Cimatti, R. (2001). El Partido Socialista en Bahía Blanca. Actividades de extensión educativa y cultural (1932-1935). En M. Cernadas (Comp.), Historia, Política y Sociedad en el Sudoeste Bonaerense (pp. 93-114). Bahía Blanca: EdiUNS.

Colegio Libre de Estudios Superiores (1953). Veintidós años de labor. 20 de mayo 1930-16 de julio 1952. Buenos Aires: CLES.

De Vito, C. (2015). Verso una microstoria translocale (Micro-Spatial History). Quaderni storici, Rivista quadrimestrale, (3), 815-833.

Di Stefano, R., Sábato, H., Romero, L. A. y Moreno, J. L. (2002). De las cofradías a las organizaciones de la sociedad civil. Historia de la iniciativa asociativa en Argentina, 1776-1990. Buenos Aires: Gadis.

Dubois, V. (1993). Les prémices de la "démocratisation culturelle". Les intellectuels, l'art et le peuple au tournant du siècle. Politix, vol. 6 (24), 36-56.

Fernandez, S. (2019). Olga Cossettini y el Colegio Libre de Estudios Superiores en Rosario (Argentina), 1939-1940. Historia y sociedad, (36), 133-159.

Ferreryra, S. (2010). La ruptura en el "interior". Una mirada de la división del Partido Socialista desde la Provincia de Buenos Aires y sus espacios locales (1955-1958). VI Jornadas de Sociología de la UNLP. Universidad Nacional de La Plata, La Plata.

Fiorucci, F. (2004). ¿Aliados o enemigos? Los intelectuales en los gobiernos de Vargas y Perón. Estudios Interdisciplinarios de América Latina y el Caribe, (15), 119-141.

Fiorucci, F. (2008). Reflexiones sobre la gestión cultural bajo el Peronismo. Nuevo Mundo Mundos Nuevos [En ligne]. DOI: 10.4000/nuevomundo.24372 Disponible en: http://journals.openedition.org/nuevomundo/24372 [Última consulta: 25/03/2013].

Fiorucci, F. (2011). Intelectuales y peronismo. 1945-1955. Buenos Aires: Biblos.

Gambini, H. (2006). Frondizi, el estadista acorralado. Buenos Aires: Javier Vergara.

Graciano, O. (2003). Intelectuales, ciencia y política en la Argentina neoconservadora - La experiencia de los universitarios socialistas. Estudios Interdisciplinarios de América Latina y el Caribe, vol. 14 (2), 51-70.

Guzmán, H. (2014). El antifascismo en Santiago del Estero: La Brasa 1934-1951. Santiago del Estero: EDUNSE.

Halperin Donghi, T. (2003). La Argentina y la tormenta del mundo. Ideas e ideologías entre 1930 y 1945. Buenos Aires: Siglo XXI.

Herrera, C. M. (2013). El intelectual como partido: Dardo Cúneo y la experiencia de Acción Socialista. Archivos de historia del movimiento obrero y de la izquierda, (3), 35-56. 
Laguarda, P. y Fiorucci, F. (2012). Intelectuales, cultura y política en espacios regionales de Argentina (siglo XX). Rosario: Prohistoria-EdUNLPam.

Lanzillotta, M. (2016). En búsqueda de voces propias. Espacios de sociabilidad intelectual en el Territorio Nacional de La Pampa (1907-1930). En C. Salómón Tarquini y M. Lanzillotta (Eds.), Redes intelectuales, itinerarios e identidades regionales en Argentina (siglo XX) (pp. 79102). Rosario: Prohistoria-EdUNLPam.

Longoni, A. y Mestman, M. (1999). Vanguardia y revolución: acciones y definiciones por una "nueva estética" argentina, 1968. En A. Pucciarelli (Ed.), La primacía de la política, Lanusse, Perón y la Nueva Izquierda en tiempos del GAN (pp. 235-263). Buenos Aires: EUDEBA.

López Pascual, J. (2011a). Intelectuales: cartas, redes e instituciones. El archivo epistolar del Colegio Libre de Estudios Superiores de Bahía Blanca en el cruce de la Historia y la Antropología (1941-1952). Revista de Estudios Marítimos y Sociales, vol. 4 (4), 107-117.

López Pascual, J. (2013a). Algunos debates intelectuales en torno a lo político y lo cultural: el Colegio Libre de Estudios Superiores en Bahía Blanca, Argentina (1940-1955). Revista Antíteses, vol. 6 (11), 236-260.

López Pascual, J. (2013b). Un abordaje a los debates intelectuales estudiantiles: las representaciones revolucionarias en algunas revistas culturales universitarias (Bahía Blanca, 1960-1961). Nuevo Mundo Mundos Nuevos [en línea]. DOI : 10.4000/nuevomundo.65345. Disponible en http://journals.openedition.org/nuevomundo/65345 [Última consulta: 15/09/2017].

López Pascual, J. (2015a). Élites y cultura. Apuntes para un estudio de la composición social de los grupos intelectuales de Bahía Blanca (1940-1960). En S. Jensen et al. (Eds.), Volúmenes Temáticos de las V Jornadas de Investigación en Humanidades: Archivos y fuentes para una nueva Historia socio-cultural, vol. 9, (pp. 91-106). Bahía Blanca: Hemisferio Derecho. http://www.jornadasinvhum.uns.edu.ar/files/5JIeHVol09.pdf [Última consulta: 28/3/2018]. López Pascual, J. (2015b). Universidad, comunidad y región: posperonismo y política cultural universitaria en el interior argentino (Bahía Blanca, 1956-1968). Historia de la Educación. Anuario, vol. 16 (1), 97-133.

López Pascual, J. (2016a). Arte y trabajo. Imaginarios regionales, transformaciones sociales y politicas públicas en la institucionalización de la cultura en Bahía Blanca (1940-1969). Rosario: Prohistoria. López Pascual, J. (2016b). ¿"Puerta y puerto del sur argentino"? Matices y debates en la representación de Bahía Blanca (Argentina) en su contexto regional a mediados del siglo XX. HISTOReLo. Revista de Historia Regional y Local, vol. 8 (15), 270-308.

López Pascual, J. (2017). Irradiación, destino y profecía: la representación de Bahía Blanca como centro cultural de la patagonia argentina (1940-1970). História Unisinos, vol. 21 (1), 5167.

López Pascual, J. (2019a). Nombrar la distinción. Estrategias de sociabilidad antiperonista en la construcción de un Otro (Bahía Blanca, Argentina, 1946). Cuadernos de Historia Cultural. Estudios de Historia de la Cultura, Mentalidades, Económica y Social (Valparaíso), (8), 138-167. 
López Pascual, J. (2019b). Con la pluma, la palabra y la política. Problemas de la extensión universitaria en Bahía Blanca a mediados del siglo XX. En J. Marcilese (Comp.), La extensión en la Universidad Nacional del Sur. Orígenes y evolución (1948-2018) (pp. 49-79). Bahía Blanca: Secretaría General de Cultura y Extensión Universitaria de la UNS.

Marcilese, J. (2006). Los antecedentes de la Universidad Nacional del Sur. En M. Cernadas (Dir.), Universidad Nacional del Sur: 1956-2006 (pp. 13-75). Bahía Blanca: EdiUNS.

Martocci, F. (2015). La política cultural del Partido Socialista en el Territorio Nacional de la Pampa: dispositivos y prácticas de intervención de sus dirigentes e intelectuales (1913-1939). Santa Rosa: UNLPam.

Martocci, F. y Laguarda, P. (2017). Escribir desde las pampas. Reflexiones sobre los vínculos interpersonales y los conflictos internos del socialismo a partir de las cartas de los hermanos Buira a Nicolás Repetto. Coordenadas. Revista de Historia Local y Regional, (4), 87-105.

Nallim, J. (2012). Debates hacia adentro: las ideas económicas del frente antifascista liberal en Argentina (1939-1943). Sociohistórica / Cuadernos del CISH, (30), segundo semestre, 35-65.

Négrier, E. (2003). Las políticas culturales en Francia y España. Una aproximación nacional y local comparada. WP, 226. Disponible en: https://www.icps.cat/archivos/WorkingPapers/wp226.pdf?noga=1 [Última consulta: 20/08/2018].

Neiburg, F. (1998). Los intelectuales y la invención del peronismo. Buenos Aires: Alianza.

Orbe, P. (2007a). La política y lo político en torno a la comunidad universitaria bahiense (1956-1976). Estudio de grupos, ideologías y producción de discursos (Tesis de Doctorado). Universidad Nacional del Sur, Bahía Blanca.

Orbe, P. (2007b). Entre la Reforma Universitaria y la revolución: análisis del discurso político de ingeniero Ricardo Ortiz como primer rector estatutario de la Universidad Nacional del Sur (19581959). $2^{\circ}$ Jornadas sobre la política en Buenos Aires en el siglo XX. Disponible en: http://historiapolitica.com/datos/biblioteca/orbe.pdf [Última consulta: 14/04/2015].

Pasolini, R. (2013). Los marxistas liberales. Antifascismo y cultura comunista en la Argentina del siglo XX. Buenos Aires: Sudamericana.

Pérez, J., Lida, C. y Lina, L. (2010). Arte y política en su condición revolucionaria y de transformación social. En J. Pérez, C. Lida y L. Lina, Lecturas, problemas y discusiones del arte argentino del último siglo. 1910-2010 (pp. 218-242). Buenos Aires: Ediciones del Centro Cultural de la Cooperación.

Petra, A. (2017). Intelectuales y cultura comunista. Itinerarios, problemas y debates en la Argentina de posguerra. Buenos Aires: FCE.

Poirrier, P. (2000). L'État et la Culture en France au XXe siècle. Paris: Librairie Générale Française. Prado Acosta, L. (2013). Concepciones culturales en pugna. Repercusiones del inicio de la Guerra Fría, el zdhanovismo y el peronismo en el Partido Comunista argentino. Nuevo Mundo Mundos Nuevos, [en línea]. DOI: 10.4000/nuevomundo.64825. Disponible en: http://nuevomundo.revues.org/64825. [Última consulta: 20/05/2014]. 
Salomón Tarquini, C. (2016). Constructores de pampeanidad: grupos de escritores de La Pampa (1957-1983). En C. Salomón Tarquini y M. Lanzillotta (Eds.), Redes intelectuales, itinerarios e identidades regionales en Argentina (siglo XX) (pp. 103-121). Rosario: Prohistoria-EdUNLPam.

Salomón Tarquini, C. y Lanzillotta, M. (2016) (Eds.). Redes intelectuales, itinerarios e identidades regionales en Argentina (siglo XX). Rosario: Prohistoria-EdUNLPam.

Sigal, S. (2002 [1991]). Intelectuales y poder en Argentina. La década del sesenta. Buenos Aires, Argentina: Siglo XXI.

Silva, H., Güenaga, R. Cignetti, A. y Cernadas, M. (1972). Bahía Blanca, una nueva provincia y diversos proyectos para su capitalización. Bahía Blanca: Universidad Nacional del Sur.

Sirinelli, J. F. (1992). Histoire des droites en France, 3: Sensibilités. Paris: Gallimard.

Sirinelli, J. F. (1998). De la demeure à l'agora. Pour une histoire culturelle du politique. Vingtième Siècle. Revue d'histoire, (57), 121-131. Versión castellana: López Pascual, J. (2015). HumHA. Revista electrónica de Historia Cultural, (1), 74-82. http://revistas.uns.edu.ar/humha/article/view/265 [Última consulta: 20/06/2017].

Spinelli, E. (2005). Los vencedores vencidos. El antiperonismo y la "revolución libertadora". Buenos Aires: Biblos.

Suasnábar, C. (2004). Universidad e intelectuales. Educación y política en Argentina (1955-1976). Buenos Aires: Flacso-Manantial.

Terán, O. (1991). Nuestros años sesenta. La formación de la nueva izquierda intelectual argentina, 1956-1966. Buenos Aires: Punto Sur.

Tortti, M. (2009). El "viejo" partido socialista y los orígenes de la "nueva" izquierda. Buenos Aires: Prometeo.

Vidal, A. (2016). Experiencias del "teatro militante" en Bahía Blanca, 1972-1978 (Tesis de Doctorado). Universidad Nacional de Sur, Bahía Blanca.

Vidal, A. (2019).Un programa cultural para la liberación: la Universidad Nacional del Sur y el “Grupo de teatro popular Eva Perón" de la Villa Miramar de Bahía Blanca (1973-1974). En M. Agesta y J. López Pascual (Eds.), Estado del arte. Cultura, sociedad y política en Bahía Blanca (pp.134-147) Bahía Blanca: EdiUNS. Disponible en: https://ediuns.com.ar/producto/estadodel-arte-cultura-sociedad-y-politica-en-bahia-blanca/ Consulta: 20/12/2019

Para citar este artículo:

López Pascual, Juliana (2020). Prácticas culturales y sensibilidades políticas en la concreción de proyectos regionales: el Colegio Libre de Estudios Superiores a mediados del siglo XX. Anuario de la Escuela de Historia Virtual, 17, 79-103. 